Relations industrielles

Industrial Relations

\title{
L'extension juridique
}

\section{Jean-Pierre Després}

Volume 1, numéro 5, janvier 1946

URI : https://id.erudit.org/iderudit/1023927ar

DOI : https://doi.org/10.7202/1023927ar

Aller au sommaire du numéro

Éditeur(s)

Département des relations industrielles de l’Université Laval

ISSN

0034-379X (imprimé)

1703-8138 (numérique)

Découvrir la revue

Citer cet article

Després, J.-P. (1946). L'extension juridique. Relations industrielles / Industrial Relations, 1(5), 4-4. https://doi.org/10.7202/1023927ar

Tous droits réservés (C Département des relations industrielles de l’Université Laval, 1946
Ce document est protégé par la loi sur le droit d'auteur. L’utilisation des services d'Érudit (y compris la reproduction) est assujettie à sa politique d'utilisation que vous pouvez consulter en ligne.

https://apropos.erudit.org/fr/usagers/politique-dutilisation/ 


\section{L'EXTENSION JURIDIQUE}

Le prolongement normal du régime des négociations collectives obligatoires est celui de l'extension juridique. En effet, par suite de l'obligation de négocier, les conventions collectives se multiplient au point qu'avant longtemps elles couvriront pratiquement toutes les industries. Il viendra un jour où il existera dans une industrie un grand nombre de conventions collectives pratiquement identiques couvrant la majorité des travailleurs de cette industrie. Il sera alors possible d'assurer l'uniformisation des conditions de travail pour tous les ouvriers d'une même industrie. En d'autres termes le régime de l'extension juridique prendra un essor considérable.

Nous disons un essor, car le régime de l'extension juridique existe déjà. . En effet, la loi de la convention collective de la province de Québec permet l'extension juridique, depuis 1934. Ici, il importe de noter que la province de Québec occupe le premier rang dans le Dominion par sa loi d'extension juridique. Après un bref exposé du principe de cette loi, nous verrons qu'aux Etats-Unis l'on considère ce régime comme l'aboutissement normal du régime des conventions collectives.

Voyons d'abord le préambule de da loi. Il déclare : " Considérant que la justice sociale impose la réglementation du travail lorsque la situation économique entrâ̂ne pour le salarié des conditions contraires à l'équité ...." Et plus loin : "Considérant qu'il est opportun d'adopter, d'étendre et de rendre obligatoires les conditions de travail consignées dans les conventions collectives', tant pour prévenir la concurrence déloyale faite aux signataires que pour établir le juste salaire et satisfaire à l'équité :n. Comme on le constate, il s'agit de stabiliser les conditions de travail à l'intérieur d'une industrie d'uniformiser pour une certaine catégorie de tra vailleurs, les ouvriers de la chaussure par exemple, les conditions de travail. Ce principe, en plus de stabiliser les salaires, égalise les conditions de concurrence entre tous les employeurs d'une même industrie.

La meilleure façon d'expliquer ce qu'est l'extension juridique est encore de citer l'article 2 de la loi qui dit : "Il est loisible au lieutenant-gouverneur en conseil de décréter qu'une convention collective relative à un métier, à une industrie, à un commerce ou à une profession, lie également tous les salariés et tous les employeurs de la province, ou d'une région déterminée de la province, dans le champ d'application défini dans ce décret ". L'extension juridique suppose donc l'existence de plusieurs conventions collectives quasi similaires ou d'une convention couvrant plusieurs entreprises.

Mais pourquoi l'extension juridique est-elle nécessaire? Simplement pour protéger les employeurs soucieux de leurs responsabilités sociales. Il n'est que juste de les protéger contre une petite minorité qui est susceptible de leur faire une concurrence condamnable en exploitant les ouvriers. De là l'application de l'extension juridique. Notons bien que la requête d'un décret relève de l'initiative des intéressés, c'est-à-dire les signatures des conventions, les employeurs et les unions ouvrières. Après l'exécution des formalités de la loi (publication d'un avis, expiration du délai ou tenue -de l'enquête prévue), "le Ministre, s'il juge que les dispositions de la convention ont acquis une signification et une importance prépondérantes pour l'établissement des con- ditions de travail, sans grave inconvénient pouvant résulter de la concurrence des pays étrangers ou des autres provinces, peut recommander l'approbation de la requête par le lieutenant-gouverneur en conseil, avec les modifications jugées opportunes, et l'adoption d'un décret à cette fin ". C'est le décret qui déclanche l'extension juridique. Les dispositions de la convention qui deviennent obligatoires sont celles relatives au salaire, $a$ la durée du travail, à l'apprentissage et au rapport entre le nombre des ouvriers qualifiés et celui des apprentis dans une entreprise donnée. Le décret peut également rendre obligatoires les dispositions de la conventions concernant la classification des opérations et la détermination des différentes catégories de salariés et d'employeurs, ainsi que celles que le lieutenant-gouverneur en conseil estime conformes à l'esprit de la loi.

On conçoit facilement que l'application d'un décret exige un organisme compétent. C'est au comité paritaire qu'il appartient d'appliquer le décret. L'article 16 stipule que "les parties à une convention collective rendue obligatoire doivent constituer un comité paritaire chargé de surveiller et d'assurer l'observance du décret, de ses modifications et de ses renouvellements ". Ajoutons que le comité paritaire " constitue une corporation et a les pouvoirs, droits et privilèges généraux d'une corporation civile ordinaire ".

Comme on le voit, l'extension juridique est synonyme de profession organisée, c'est-à-dire, réglementation des conditions de travail de toute une profession par les intéressés, employeurs et ouvriers. A notre avis, c'est le terme de l'évolution normale des relations patronales et ouvrières:

Le régime des négociations collectives obligatoires devrait nous conduire rapidement à la multiplication des décrets. Nous avons déjà fait l'expérience de l'extension juridique et il y a lieu de croire que nous devons persister dans la même voie. D'ailleurs, si nous tenons compte des courants d'idées qui circulent aux EtatsUnis, nous sommes à l'avant-garde. C'est William $\mathbf{H}$. Davis, ex-président du National War Labor Board qui déclarait : "Industry-wide collective bargaining seems a logical next development. It makes for greater stability through out an industry, more responsible unions, and puts management on a more fair and equitable competitive basis so far as wage costs are concerned. It seems to me that what we principally need now is more organization among employer and management groups. Such organization would do much to promote an equality of bargaining power between management and labor "). Dans la province de Québec, la loi de la convention collective est l'application de ce principe et cela démontre que notre législation ouvrière ne le cède à aucune autre sur le continent américain.

L'extension juridique de la convention collective représente la formule la plus efficace d'organisation du marché du travail, tant par les employeurs que par les unions ouvrières. Elle crée un équilibre entre ces deux forces qui se rencontrent inévitablement sur le marché du travail. Elle a surtout le mérite d'être essentiellement démocratique car elle reconnait à la fois les droits et les obligations du patronat et du travail organisé.

Jean-Pierre Després. 